\title{
IUFD incidence, causes and complications: a retrospective study done at a tertiary care centre in greater Noida, India
}

\author{
Shehla Jamal, Shelly Agarwal* \\ Department of Obstetrics and Gynecology, School of Medical Sciences and Research, Greater Noida, Uttar Pradesh,
} India

Received: 23 September 2017

Accepted: 30 October 2017

*Correspondence:

Dr. Shelly Agarwal,

E-mail: drshellyagarwal@yahoo.com

Copyright: $\odot$ the author(s), publisher and licensee Medip Academy. This is an open-access article distributed under the terms of the Creative Commons Attribution Non-Commercial License, which permits unrestricted non-commercial use, distribution, and reproduction in any medium, provided the original work is properly cited.

\begin{abstract}
Background: Demise of a fetus is not only a cause of distress to the parents but also leaves the obstetrician with little choice. Managing such a pregnancy and counselling of the patient becomes a difficult task for us. Early assessment and timely intervention are the key approaches for reducing the incidence of still births globally. By such a strategy, peripartum complications can also be reduced. The current study was undertaken with an aim to assess the incidence of IUFD, causes and peripartum complications associated, in order to formulate a management protocol at our centre.

Methods: This is a retrospective study done over a period extending from September 2014 to October 2015. IUFD was taken as absent fetal heart sounds beyond 20 weeks gestation which was confirmed by sonography. Maternal and fetal records were analysed for studying demographic profile, obstetric details including present and past complications, along with evaluation of fetal parameters.

Results: Total number of deliveries over this period was 995 and cases of IUFD reported were 56. Hence calculated proportion was $5.62 \%$. Majority of the cases were unbooked $(66 \%)$ and presented to obstetric casualty. Maximum cases were found in primi gravida patients, i.e., $35.7 \%$ and most of the cases were identified at a gestational age of 2024 weeks, $32.1 \%$. Hypertensive disorders of pregnancy, $41 \%$ and Anaemia, 25\% were found to be the leading maternal causes at our centre. Whereas congenital anomalies 23.2\% and Antepartum haemorrhage $30.3 \%$ were the commonest causes in fetal and placental factors studied. Prolonged labor was observed in 33.9\% and Atonic PPH was present in $21.4 \%$ patients. ARF was present in $3.5 \%$ and DIC was also found in $3.5 \%$ of the cases. However, no explainable cause could be found in $12.5 \%$ of the patients.

Conclusions: Barring the unexplained fetal losses, most of the causes that were ascertained in present study were avoidable. This highlights the importance of our need to understand the avoidable causes of IUFD and to enforce the need of adequate antenatal care so as to timely identify the risk factors. In addition, the necessity of pre-conceptional counselling in order to avoid complications and recurrence must also be emphasized.
\end{abstract}

Keywords: IUFD, Pre-conceptional counselling, Retrospective study

\section{INTRODUCTION}

Intrauterine fetal deaths and stillbirths, defined as fetal demise after 20 weeks of gestation, has profound emotional, psychiatric and social effects on both parents and their families. ${ }^{1}$ Prevalence of IUFD and stillbirths is the direct indicator of the quality of antenatal care in that society. ${ }^{2}$ Annual Report of the Confidential Enquiries into Still Births and Death in Infancy (CESDI) identified suboptimal care as being evident in half of such pregnancies. ${ }^{3}$ The share of developing countries is as much as two thirds of the total perinatal mortality occurring in the world. Worldwide over 2.6 million of still births happen annually. ${ }^{4}$ Out of these, statistics reveal 
that $23.2 \%$ (almost one fourth of IUFDs), were from India, the highest for any nation. In fact, India is in the top half of the chart with 22 Still Births per 1000 live births. ${ }^{4}$ This problem needs to be addressed, especially in our country, where inadequate antenatal care is compounded by inaccessibility to healthcare facilities.

Antepartum fetal deaths contribute to about seventy five per cent of the perinatal mortality. ${ }^{2}$ The fetal deaths are related to maternal (5-10\%), placental (20-35\%) or fetal (25-40\%) complications. Tulip, Extended Wigglesworth, Modified Aberdeen are some classifications used for classifying the causes for fetal death. ${ }^{5}$ Tulip classification uses maternal, fetal and placental causes whereas, Aberdeen and Wigglesworth use maternal and fetal factors only. Irrespective of the method of classification used, it is a well-established fact that adequate prenatal care is associated with better pregnancy outcomes. Early booking, adequate antenatal care early identification of the risk factors and timely intervention helps in preventing perinatal morbidity and mortality. The main area of concern in our area of study (western UP), is still inadequate access to healthcare facilities. Patients presented in obstetric emergency, maximum being referred from outside, thus leaving us with little time to act and salvage. Identification of the major contributory factors will help us in imparting better patient care. We undertook this study to identify the most common factors and etiology of IUFD at our centre.

The objective of our study is to identify the incidence, causes and peripartum complications associated with pregnancies complicated with IUFD at our tertiary care centre in Greater Noida.

\section{METHODS}

A retrospective analytical study done in the Department of Obstetrics and Gynaecology, School of Medical Sciences and Research, Greater Noida. The study was carried out from September 2014 to October 2015.

Women with sonologically confirmed diagnosis of IUFD, beyond 20 weeks (intermediate and late IUFDs) were included in the study. Patients were admitted through ANC clinic and Obstetrics emergency. A total of 56 cases of IUFD were identified in this period. Retrospective analysis of all the records were done.
Parameters studied were, demographic profile, obstetric details of the present and past pregnancies, gestational age at the time of diagnosis, and any other medical or obstetrical complication associated was also noted. Peripartum events were analysed for any complications.

Investigations recorded on the case sheet were also studied, like, haemogram, blood group and Rh factor, urine examination, HIV1 and 2, $\mathrm{HBs} \mathrm{Ag}$, Anti $\mathrm{HCV}$, VDRL, random blood sugar, LFT, KFT, and serum TSH levels. Special investigations were also studied, if done, according to the relevance of the case. Recorded data was studied to look for the probable cause and any peripartum complications. Results were obtained using the percentage method.

\section{RESULTS}

A total of 56 cases of IUFD occurred out of 995 deliveries in the study period between September 2014 to October 2015. The proportion of IUFD at our centre is $5.62 \%$. Majority of the patients were unbooked $(66.6 \%)$ and presented through obstetric casualty. After detailed evaluation it was found that booking was done either very late or the patients had irregular and infrequent antenatal visits.

Table 1: Demographic parameters.

\begin{tabular}{|lllll|l|}
\hline $\begin{array}{l}\text { Age } \\
\text { (yrs) }\end{array}$ & $\begin{array}{l}\mathbf{N} \\
(\%)\end{array}$ & Parity & $\begin{array}{l}\mathbf{N} \\
(\%)\end{array}$ & $\begin{array}{l}\text { Gest age } \\
(\text { wks })\end{array}$ & $\begin{array}{l}\mathbf{N} \\
(\%)\end{array}$ \\
\hline $16-20$ & $\begin{array}{l}19 \\
(33.9 \%)\end{array}$ & G1 & $\begin{array}{l}20 \\
(35.7 \%)\end{array}$ & $20-24$ & $\begin{array}{l}18 \\
(32.1 \%)\end{array}$ \\
\hline $21-25$ & $\begin{array}{l}18 \\
(32.1 \%)\end{array}$ & G2 & $\begin{array}{l}13 \\
(23.2 \%)\end{array}$ & $25-28$ & $\begin{array}{l}12 \\
(21.4 \%)\end{array}$ \\
\hline $26-30$ & $\begin{array}{l}11 \\
(19.6 \%)\end{array}$ & G3 & $\begin{array}{l}14 \\
(25.0 \%)\end{array}$ & $29-34$ & $\begin{array}{l}17 \\
(30.3 \%)\end{array}$ \\
\hline $31-35$ & $\begin{array}{l}6 \\
(10.7 \%)\end{array}$ & G4 & $\begin{array}{l}5 \\
(8.9 \%)\end{array}$ & $35-40$ & 6 \\
\hline$>40$ & $\begin{array}{l}2 \\
(3.5 \%)\end{array}$ & $>$ G5 & $\begin{array}{l}4 \\
(7.1 \%)\end{array}$ & $>40$ & $\begin{array}{l}(10.7 \%) \\
(5.3 \%)\end{array}$ \\
\hline
\end{tabular}

Majority, $77.1 \%$ complained of reduced fetal movements. Majority of the patients were in the age group of 16-20 years, $33.9 \%$, and maximum incidence was found in primigravida mothers, $35.7 \%$. Maximum distribution at the age of diagnosis was at 20-24 weeks $32.1 \%$.

Table 2: Incidence according to maternal, fetal and placental causes.

\begin{tabular}{|llllll|}
\hline Maternal N (\%) & & Fetal & N $(\%)$ & Placental N $(\%)$ & $17(30.3 \%)$ \\
\hline HDP & $23(41 \%)$ & Congenital anomaly & $13(23.2 \%)$ & Abruption & $17(12.5 \%)$ \\
\hline Anemia & $14(25 \%)$ & Twin & $9(16.0 \%)$ & Prvia & $1(1.7 \%)$ \\
\hline Medical disorder & $7(12.5 \%)$ & Malpresentation & $8(14.2 \%)$ & Cord prolapse & $1(10.7 \%)$ \\
\hline Infection & $9(16.7 \%)$ & FGR & $11(19.6 \%)$ & Infection & $6(25)$ \\
\hline Others & $3(5.3 \%)$ & Others & $15(26.7 \%)$ & Others & $25(44.6 \%)$ \\
\hline
\end{tabular}


Labor had to be induced in $50 \%$ cases, and $41.0 \%$ went into spontaneous labor, whereas abdominal delivery was performed in $8.9 \%$ of the patients albeit for different indications.

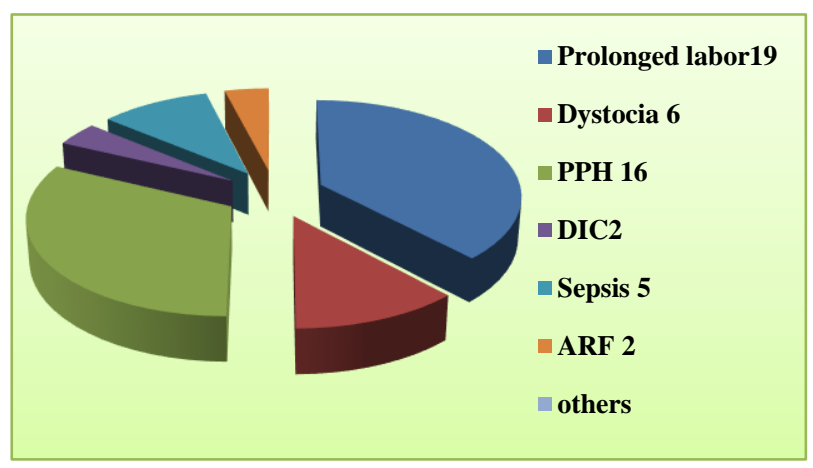

Figure 1: Distribution of maternal complications.

Hypertensive disorders of pregnancy were the leading maternal cause, $41 \%$. Congenital anomalies accounted for $23.2 \%$ in fetal causes, and $30.3 \%$ of still births were due to abruption, amongst the placental causes. $12.5 \%$ cases remained unexplained.

Prolonged labor was the most common labor complication seen in $33.9 \%$ of them. Sepsis complicated $8.92 \%$ of the total cases. Autopsy and Karyotyping were suggested to the patients but it was refused.

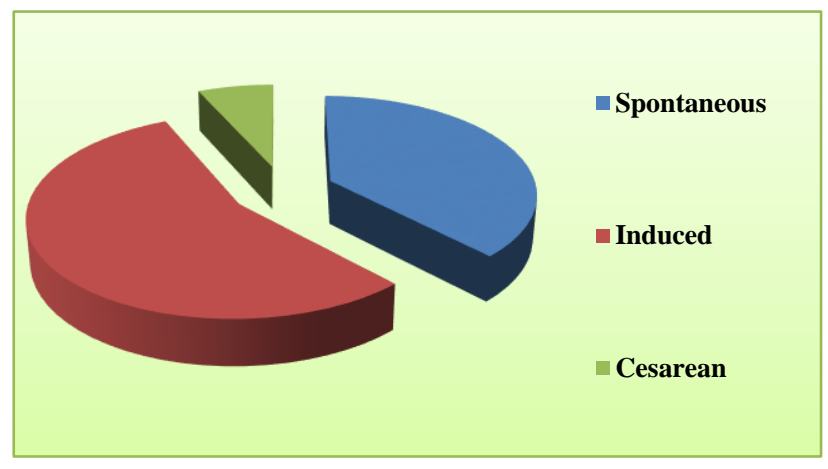

Figure 2: Distribution of mode of labor.

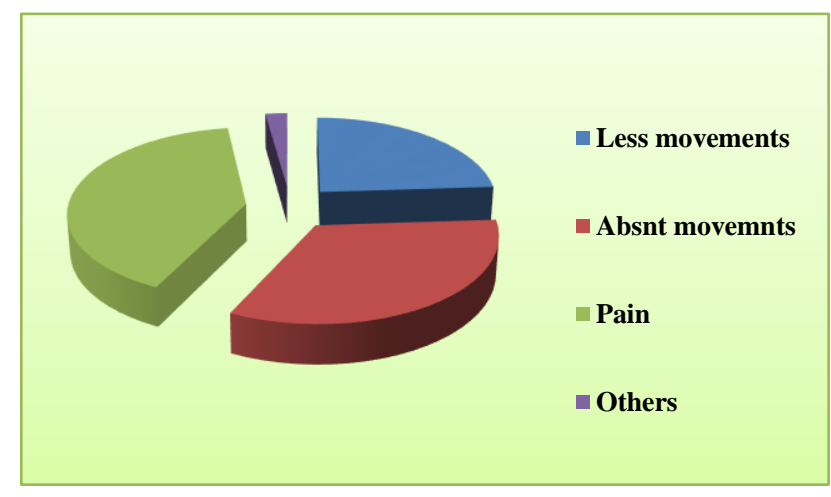

Figure 3: Distribution of chief complaint at the visit.

\section{DISCUSSION}

Intrauterine fetal demise causes distress and psychological trauma to the patients and their family. Since long various attempts have been made to reduce its occurrence. Despite decline in overall perinatal mortality rate, IUFD still occurs at an unacceptably high level. Present study observed an incidence of $5.62 \%$ at our centre. Ours is a tertiary care centre at Greater Noida, where patients are generally referred when IUFD has already occurred. Different regions in Uttar Pradesh have recorded different stillbirth rates. In a study done in Uttarakhand, the rate of stillbirth was 49 per $1000 \mathrm{LB}$, whereas national average is that of 38 per 1000 Live Birth. ${ }^{6}$

In present study, incidence of IUFD was higher in emergency admissions, $66 \%$ as compared to $33.9 \%$ in booked cases. Kameshwaram et al observed five times higher still birth rate in emergency cases. ${ }^{7}$ Al Kadri et al found $70 \%$ risk of IUFD in patients not receiving antenatal care. ${ }^{8}$

Maximum incidence was found in the age group of 16-20 years $(33.9 \%)$, indicating that teenage is the group most commonly affected. Similarly, as reported by Desai S et al in her study, incidence in teenage group was $30.76 \%$. $^{9}$ Teenage pregnancies are mostly unplanned and are at high risk for HDP, Anemia as well as labor complications. Higher maternal age was not a significant contributory factor in our study.

Parity is an important factor which influences pregnancy outcome. In the present study, majority of the cases were present in primigravida mothers $35.7 \%$. Similar observation was made by Desai $S$ et al in their study (46.15\%). ${ }^{9}$ However, study done by Raymond E G et al demonstrated a higher still birth rate in multigravida females. ${ }^{10}$

In present study, perception of reduced fetal movements was found in $77.1 \%$ cases and rest presented with absent fetal movements, pain abdomen, Leaking per vaginum. Majority, however, presented with two or more complaints.

In present study diagnosis of fetal death was made at the gestation of 20-24 weeks in maximum number of cases $32.1 \%$. And majority of these cases had Hypertensive Disorders of Pregnancies (HDP), as a complicating factor. Pregnancies with early IUFD had Congenital anomalies as the most common factor.

To reduce the burden on health care facilities and to prevent recurrence, retrospection and introspection becomes mandatory. In our study hypertensive disorders of pregnancy caused $41 \%$ of the total losses. In a study done by Patel S HDP was found in $33.7 \%$ of the cases. ${ }^{11}$ 
Thus, HDP maintains the legacy of being the most common etiological factor in maternal causes. Second leading maternal cause was Anemia, 25\%, (moderate and severe), which is a highly preventable cause. Despite exhaustive efforts to prevent and treat anemia by the Government of India, the goal still remains at large. Other maternal causes in our study were infections $16.7 \%$ and medical disorders $12.5 \%$.

The fetal death rate after 28 weeks has declined since 1990, whereas deaths from 20-27 weeks are largely unchanged. This highlights the importance of evaluation of causes for intermediate IUFD. In present study, amongst the fetal cuases, $23.2 \%$ stillbirths were due to gross congenital anomalies and others were due to fetal growth restrictions $19.6 \%$. Anjali C et al and Kumar et al reported $10.5 \%$ and $10 \%$ cases due to congenital malformation.

In the placental factors evaluated, abruption was found in $30.3 \%$ cases, placenta previa in $12.5 \%$ cases and cord prolapse was seen in $1.7 \%$ cases. Placental causes, especially placental insufficiency is more likely to recur. Thus, the study of these factors is of paramount importance.

In current study, only $12.5 \%$ cases had no ascertainable cause in contrast to the observation made by Desai $\mathrm{S}$ et al. They found no cause in as high as $57.69 \%$ of the cases. In a similar study done by Anjali $\mathrm{C}$ et al, no risk factor was found in $19.05 \%$ of the total cases. ${ }^{6}$ As all clinical studies are limited by many factors, including advanced tests for determination of the case, our study also was limited by the same factor. Although $41 \%$ patients went into spontaneous labor, induction was done in $50 \%$ cases and abdominal delivery was performed in $8.92 \%$ of the cases.

Prolonged labor was the commonest labor complication $33.9 \%$, followed by atonic PPH in $21.4 \%$ and shoulder dystocia in $10.7 \%$. Two cases each were there who developed ARF and DIC. There was one maternal mortality also, where the patient was a case of ecclampsia complicated with ARF.

Stillbirth risk is higher in a woman with prior still birth and recurrence is also noted with fetal growth restriction, pre-ecclampsia and abruption. ${ }^{12}$ Thus, it is very important to find out the probable and possible cause of fetal demise. Modifiable risk factors are best dealt with during peri-conceptional care. However, inadequate access to health care facilities and irregular antenatal visits on the part of the patient, limit the quality of health care.

A significant proportion of IUFD is preventable by patient education, attention to the warning signs, regular visits and early referral. Present study was limited by not performing of autopsy and tissue biopsy. Further tests can be conducted to assign the most possible cause for counselling the family and minimise the recurrence.

\section{CONCLUSION}

Not all the IUFDs are preventable, neither a cause can be assigned to every case. But the rates can be brought down by the joint efforts at all the levels. Early booking, identification of high risk cases, timely intervention and referral are the key approaches to reduce the incidence of IUFD and prevent recurrence. HDP, anemia, abruption, congenital anomalies, are the commonest causative factors. And most of these factors are preventable, can be diagnosed and managed early. Psychological trauma associated with fetal demise is profound. Hence close antepartum surveillance and hospital deliveries should be promoted.

\section{Funding: No funding sources}

Conflict of interest: None declared

Ethical approval: The study was approved by the Institutional Ethics Committee

\section{REFERENCES}

1. Clinical practice guideline. Investigations and management of late fetal intrauterine death and still birth. Institute of Obstetrician and Gynecologist Royal college of Physicians Ireland and Directorate of clinical program health service executive, Version 1.0 , guideline no 4 oct 2011, revised 2015.

2. Rchardus, Jan H, Graafmans, Wilco C., VerlooveVanoricke, S Pauline, Mackenbach, Johan P. The perinatal mortality rate as an indicator of quality of care in international comparisons. Medical Care. 1999;36(1):54-6.

3. Confidential enquiry into still birth AND death in infancy, $8^{\text {th }}$ annual report; London: Maternal and child Health Research Consortum; 2001 Available at http:// www.cmace.org.uk/getattachment

4. Cousens S, Blencowe H, Stanton C, Chou D, Ahmed S, Steinhardt L, Creanga AA, Tunçalp Ö, Balsara ZP, Gupta S, Say L. National, regional, and worldwide estimates of stillbirth rates in 2009 with trends since 1995: a systematic analysis. Lancet. 2011 Apr 22;377(9774):1319-30.

5. Korteweg FJ, Gordijn SJ, Timmer A, Erwich JJ, Bergman KA, Bouman K, Ravise JM, Heringa MP, Holm JP. The Tulip classification of perinatal mortality: introduction and multidisciplinary interrater agreement. BJOG: Int J Obstet Gynecol. 2006 Apr 1;113(4):393-401.

6. Anjali C, Gupta V. Epidemiology of intrauterine fetal deaths: A study in tertiary referral centre in Uttarakhand. IOSR-JDMS. 2014;13(3):3-6.

7. Kameshwaram C, Bhatia BD, Hat BV, Oumachigui A. Perinatal mortality: a hospital based study. Indian Pediatr J. 1993;30:997-1001.

8. Al-Kadri HM, Tamim HM. Factors contributing to intra-uterine fetal death. Arch Obstet Gynecol. 2012;286(5):1109-16. 
9. Desai S, Sawant V. Evaluation of clinical and aetiological factors for intrauterine fetal death. Online Int Interdiscipl Res J. 2014;4(1).

10. Raymond EG, Cnattingius S, Kiely JL. Effects of maternal age, parity and smoking on the risk of Still Birth. BJOG. 1994;101:301-6.

11. Patel S, Thaker R, Shah P, Majumdar S. Study of causes and complications of intrauterine fetal death
(IUFD). Int J Reprod Contracept Obstet Gynecol. 2014 Dec;3(4):931-5.

Cite this article as: Jamal S, Agarwal S. IUFD incidence, causes and complications: a retrospective study done at a tertiary care centre in greater Noida, India. Int J Reprod Contracept Obstet Gynecol 2017;6:5483-7. 